\title{
DC Shunt Motor Control using Wavelet Network
}

\author{
Mohammed Kamil Hilfi \\ Department of Electrical Engineering \\ California State University, Fullerton
}

800 N. State College Blvd, Fullerton, CA 93834

\begin{abstract}
In this paper, a dc shunt motor with fixed speed control system is presented, a wavelet neural network control scheme is proposed to control the speed of shunt DC motor, the wavelet neural network (WNN) is used and optimized using particle swarm optimization (PSO) algorithm. The performance is measured depending on values of mean square error (MSE)
\end{abstract}

The work is divided into two sections, in the first section, the feedback control system is implemented using wavelet neural network, buck DCIDC converter and DC shunt motor model, the parameters of wavelet neural network is optimized using PSO. In the second section, number of measurements are used to calculate the response of DC shunt motor depending on the different torque values.

Simulation of DC Shunt motor is specially designed to test and implement the proposed control schemes using MATLAB Version 7.12.0.635(R2011a).

\section{General Terms}

DC shunt motor, speed control.

\section{Keywords}

DC shunt motor, speed control, wavelet neural network, PSO.

\section{INTRODUCTION}

In recent years, DC motor have been widely applied as an important part in many areas of different industrial applications. A motor is an electromechanical device which is used to convert an electrical energy into rotary mechanical energy [1]. A DC motor is an electric motor that operates based on the direct current (DC) electricity. DC motors were used to operate machines with a good response, so they eliminate the use for a local steam engine or internal combustion engine that the first electric vehicles motive power supplied from direct rechargeable battery which used for DC motors operation. Today DC motors are used in many applications; for instance, in small size toys and disk drives, or in large sizes to operate steel rolling mills and paper machines, and the power electronic devices are used with DC motors [2].

The advantages in DC motors such as flexibilities, high reliabilities, and low costs, give the DC motors ability to use in wide areas of industrial applications such as robot manipulators and home appliances where speed and position control of motor are required, so they can be used to rotate pumps, fans, compressors, wheels, etc [3]. The speed control of a DC motor is very important in applications where precision and protection are required. The purpose of a motor speed controller is to generate the control signal which is responsible for representing the required speed with a small error and to run the motor at that speed [4].

\author{
David Cheng \\ Department of Electrical Engineering \\ California State University, Fullerton \\ 800 N. State College Blvd, Fullerton, CA 93834
}

There are two types of motors which are DC motors and AC motors. AC motors are generally used in high power single or multi-phase industrial applications where a constant rotational torque and speed are required to control large loads; however, DC motors have better starting torque than AC motors [5].

The speed of a DC motor is directly proportional to the supply armature voltage [6]. A DC motor provides an excellent speed control for acceleration and deceleration with an effective and simple torque control [7]. The connection of the DC motor's power supply directly to the field of the DC motor allows for precise voltage control, which is necessary with speed and torque control applications. DC motor is considered as a Single Input Single Output (SISO) system that has torque/speed characteristics compatible with most mechanical loads. This makes the DC motor controllable over a wide range of speeds with proper adjustment of the terminal voltage [8]. In a simple DC motor electricity, a magnetic field is used for generating the required torque which is used for rotating the motor. Both voltage and current have an effect in the response of the DC motor. That means the applied voltage is related with the speed of the motor while the current which passes through the armature windings is related with the torque; therefore, it can be used the applied voltage for controlling the speed while it can be used the current for controlling the torque. The increasing of the torque in the shaft makes the motor draw more current to maintain the speed.

\section{SPEED CONTROL METHODS FOR DC MOTOR}

The motor speed can be controlled by controlling the armature voltage or the field voltage. It is obvious that the speed control is possible by varying the following.

- $\quad$ Flux per pole, $\varphi$ (Flux Control).

- Resistance of armature circuit, $\mathrm{Ra}$ ( Rheostatic Control).

- $\quad$ Armature applied voltage, (Voltage Control).

The usage of the above methods (with resistance control) have some disadvantages such as a large amount of power is wasted in the controller resistance. Hence, the efficiency is decreased. This needs expensive arrangement for dissipation of heat produced in the controller resistance. It gives speeds below the normal speed. Therefore, these methods are less adaptive. Electronic techniques are used for speed control. These techniques provide higher efficiency, greater reliability, and quick response [9]. One of the such techniques is Pulse Width Modulation (PWM) with DC/DC converter. This technique will be used in the present work to control the speed of the DC motor. In general, the control of a system is difficult due to their high nonlinearity properties. To overcome this difficulty, wavelet neural network controller can be developed. 


\section{WAVELET NEURAL NETWORK}

Figure 1 shows the architecture of three layers wavelet neural network. The input layer consists of $\mathrm{M}$ nodes, the hidden layer consists of $\mathrm{N}$ nodes, and the output layer consists of $\mathrm{J}$ nodes. The impulse function of the hidden layer is wavelet basis function, and the impulse function of output layer is sigmoid function $[10,11]$. The input vector is $X=\left[\mathrm{x}_{1}, \mathrm{x}_{2}, \ldots \ldots, \mathrm{x}_{\mathrm{M}}\right]$, the actual output vector is $y=\left[y_{1}, y_{2} \ldots \ldots y_{J}\right]$, the expected output is $y_{d}=\left[y_{d_{1}}, y_{d_{2}}, \ldots \ldots ., y_{d_{\mathrm{J}}}\right]$. The parameters $\mathrm{M}, \mathrm{N}, \mathrm{J}$ are the nodes number of the input layer, the hidden layer, and the output layer, respectively. The parameters $w_{i n, m}$ and $w_{o j, n}$ are the connecting weights between the input layer and the hidden layer, and between the hidden layer and the output layer, respectively.

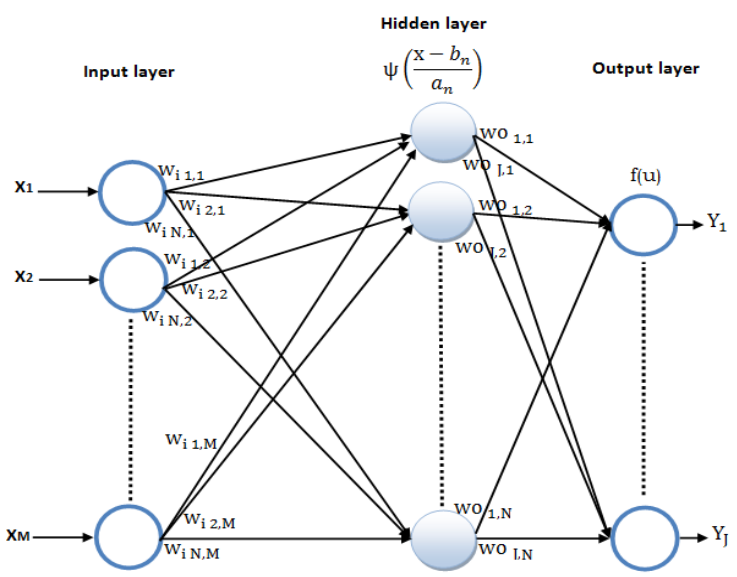

Fig 1: WNN Architecture [10]

The computation functions is as follows [12]:

$Y_{j}=f(u)=f\left[\sum_{n=1}^{N} w_{o j, n} \psi_{a n, b n}\left(\sum_{m=1}^{M} w_{i n, m} x_{m}\right)\right]$

$\mathrm{a}, \mathrm{b} \in \mathrm{R}, \quad \mathrm{a}>0$

$\mathrm{f}(u)=\frac{1}{1+\mathrm{e}^{-u}}$

The sum of the output layer deviations is MSE,

MSE $=\frac{1}{N_{s}} \sum_{i=1}^{N_{s}} \sum_{j=1}^{J}\left(y_{d_{j}}(i)-y_{j}(i)\right)^{2}$

The wavelet network operation consists of two phases. In the first phase, the network architecture is determined for certain application. In the second phase, the parameter of the network are updated so that the approximation errors are minimized.

PSO algorithm to select optimal values for wavelet neural network parameters $\left(\mathrm{a}, \mathrm{b}, w_{i n, m}\right.$ and $\left.w_{o j, n}\right)$.

\section{THE PARTICLE SWARM OPTIMIZATION (PSO)}

Particle Swarm Optimization (PSO) is an evolutionary optimization technique which is introduced by Eberhart and Kennedy in 1995. One of the main streams of artificial life research is to examine how natural creatures behave as a swarm and reconfigure the swarm models inside a computer. School of fishes and swarm movement behavior, while they are searching for food [13].

The particle swarm optimization algorithm is used to find optimal parameters for the wavelet neural network in the training phase, and that will minimize the error function in competitive time. The advantages of using particle swarm optimization (PSO) algorithm as compared with other techniques are that the PSO is computationally inexpensive, easily implemented, and does not require gradient information of an objective function, but only its values [14].

This modification can be represented by the concept of velocity. Velocity of each agent can be modified by the following equation [15]

$v_{i}^{k+1}=w_{i}^{k}+c_{1} \operatorname{rand} 1\left(\right.$ pbest $\left._{i}-s_{i}^{k}\right)+c_{2} \operatorname{rand} 2\left(\right.$ gbest $\left._{i}-s_{i}^{k}\right)$

Using the above equation, a certain velocity, which gradually gets close to pbest and gbest can be calculated. The current position (searching point in the solution space) can be modified by the following equations.

$w=w_{\max }-\frac{\left(w_{\max }-w_{\min }\right)}{\text { iter }_{\max }}$

$s_{i}^{k+1}=s_{i}^{k}+v_{i}^{k+1}$

Where;

(w) is weight function, $\left(v_{i}^{k}\right)$ is velocity of agent $i$ at iteration $k$, ( $c_{1}$ and $c_{2}$ ) are weight factors, (gbest) is global best of the group, (pbest $t_{i}$ ) is personal or local best of agent $i$, $\left(\operatorname{rand}_{1}\right.$ and rand $\left._{2}\right)$ are random numbers between 0 and $1,\left(\mathrm{~s}_{\mathrm{i}}^{\mathrm{k}}\right)$ is current position of agent $\mathrm{i}$ at iteration $\mathrm{k},\left(\mathrm{w}_{\max }\right)$ is initial weight, $w_{\min }$ is final weight, $\left(\right.$ iter $_{\max }$ ) is maximum number iteration.

The general flow chart of PSO is shown in Figure 2, and the step procedure is detailed below [16].

Step. 1 Generation of initial condition of each agent

Initial searching points $\left(s_{i}^{0}\right)$ and velocities $\left(v_{i}^{0}\right)$ of each agent are usually generated randomly within the allowable range. The current searching point is set to pbest for each agent. The best-evaluated value of pbest is set to gbest and the agent number with the best value is stored.

Step. 2 Evaluation of searching point of each agent

The objective function value is calculated for each agent. If the value is better than the current pbest of the agent, the pbest value is replaced by the current value. If the best value of pbest is better than the current gbest, gbest is replaced by the best value, and the agent number with the best value is stored.

Step. 3 Modification of each searching point: The current search point of each agent is changed using Equations (1), (2), and (3).

Step. 4 Checking the exit condition: If the current iteration number reaches the predetermined maximum iteration number, then exit. Otherwise, go to step 2.Figure2 refer to the General flow chart of PSO. 


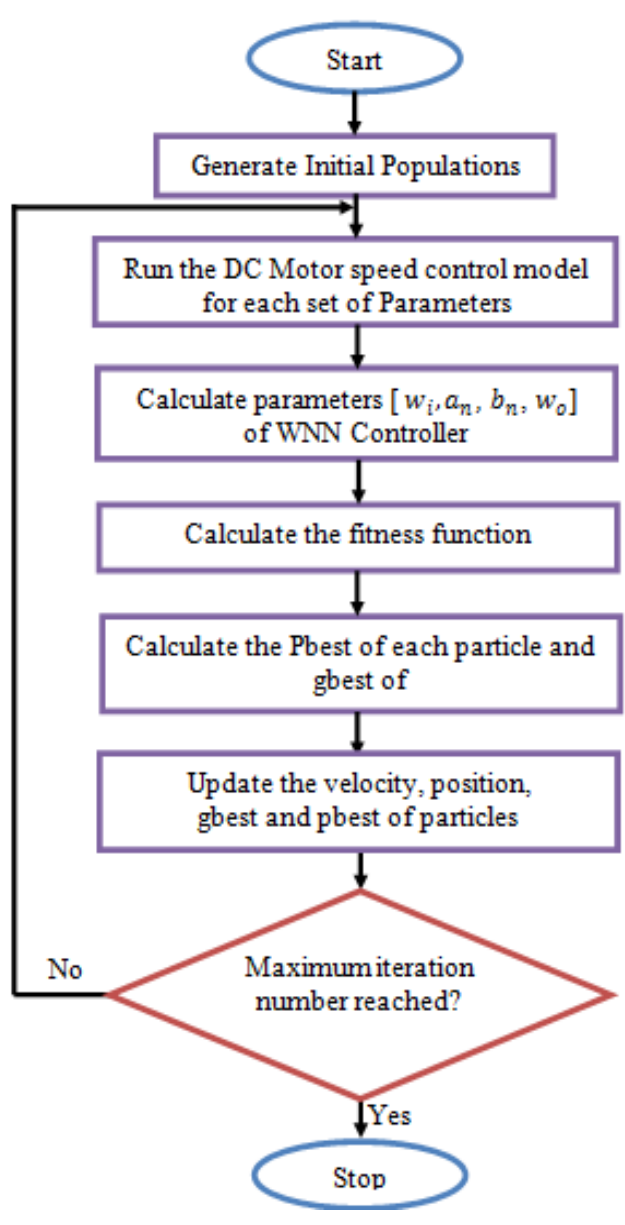

Fig 2: The Flowchart of the Typical PSO [17]

\section{DC shunt Motor Mathematical Model}

The dynamical model of DC shunt, series and permanentmagnet motors are presented in this section [18]. In shunt motor, the field circuit is connected in parallel with the armature. Adjustable resistor $R_{a d j}$ is normally connected in series with the field circuit for speed control. DC shunt motor has the following dynamical model:

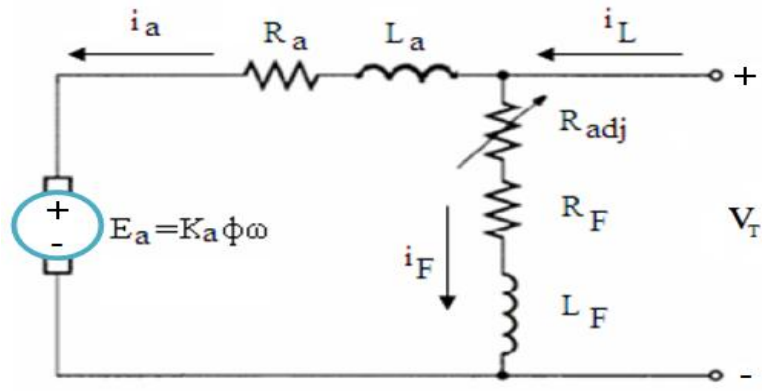

Fig 3: Equivalent circuit to the DC motor

The mathematical model of the electromechanical system is as the following.

$\mathrm{i}_{\mathrm{a}}=\left(\mathrm{V}_{\mathrm{T}}-\mathrm{E}_{\mathrm{a}}\right) / \mathrm{R}_{\mathrm{a}}$

$\dot{\theta}=w$
The motor converts the electrical armature current into a mechanical torque applied to the shaft.

$\mathrm{T}_{\mathrm{m}}=\mathrm{K}_{\mathrm{a}} \emptyset \mathrm{i}_{\mathrm{a}}$

The applied torque produces an angular velocity $\omega$ according to the inertia $\mathrm{J}$ and friction $\mathrm{B}$ of the motor and load.

$J \frac{d w}{d t}=T_{m}-B w-T_{L}$

Equations (4), (5) and (6) represent the nonlinear dynamical behavior of a DC shunt motor including the nonlinearity of the magnetization curve of the ferromagnetic material of the machine.

$\mathrm{L}_{\mathrm{F}} \frac{\mathrm{di}_{\mathrm{F}}}{\mathrm{dt}}$

$=V_{T}-\left(R_{F}+R_{a d j}\right) i_{F}$

$\mathrm{L}_{\mathrm{a}} \frac{\mathrm{di}_{\mathrm{a}}}{\mathrm{dt}}=\mathrm{V}_{\mathrm{T}}-\mathrm{R}_{\mathrm{a}} \mathrm{i}_{\mathrm{a}}-\mathrm{K}_{\mathrm{a}} \emptyset \mathrm{w}$

$\mathrm{J} \frac{\mathrm{dw}}{\mathrm{dt}}=\mathrm{K}_{\mathrm{a}} \emptyset \mathrm{i}_{\mathrm{a}}-\mathrm{T}_{\mathrm{L}}$

where ;

$\mathrm{T}_{\mathrm{m}}$ : electromagnatic torque,

B : viscous friction

$L_{F}$ : field winding inductance,

$i_{F}$ : field current,

$V_{T}$ : terminal voltage and

$\mathrm{R}_{\mathrm{f}}+\mathrm{R}_{\mathrm{adj}}$ : total field resistance,

$\mathrm{L}_{\mathrm{a}}$ : armature winding inductance,

$i_{a}$ : armature current,

$\mathrm{R}_{\mathrm{a}}$ : armature resistance,

$K$ : constant related to the design of the machine,

$\emptyset$ : flux per pole

$w$ : rotational speed of the rotor

$J$ : rotor and load moment of inertia,

$T_{L}:$ load torque

Table (1) shows the physical parameters values which are used for DC shunt motor equivalent circuit.

Table(1): DC Motor Physical Parameters Values

\begin{tabular}{|c|c|c|}
\hline Parameter & Value & Unit \\
\hline $\mathrm{R}_{\mathrm{a}}$ & 0.5 & $\mathrm{Ohm}$ \\
\hline
\end{tabular}




\begin{tabular}{|c|c|c|}
\hline $\mathrm{L}_{\mathrm{a}}$ & 0.0015 & Henry \\
\hline $\mathrm{L}_{\mathrm{F}}$ & 10 & Henry \\
\hline $\mathrm{K}_{\mathrm{b}}$ & 0.05 & unit less \\
\hline $\mathrm{K}_{\mathrm{m}}$ & 0.05 & unit less \\
\hline $\mathrm{B}$ & 0.0001 & Nms \\
\hline $\mathrm{J}$ & 0.00025 & $\mathrm{Kg} \cdot \mathrm{m}^{2}$ \\
\hline
\end{tabular}

Figure (4) shows the block diagram of feedback control system using wavelet neural network of two neurons in the input layer, thirty neurons in the hidden layer and one neuron in the output layer and morlet function is used. The wavelet neural network parameters $w_{i}, a_{n}, b_{n}, w_{o}$ are optimized using partial swarm optimization, and the output of the wavelet controller connected to DCIDC converter type buck.

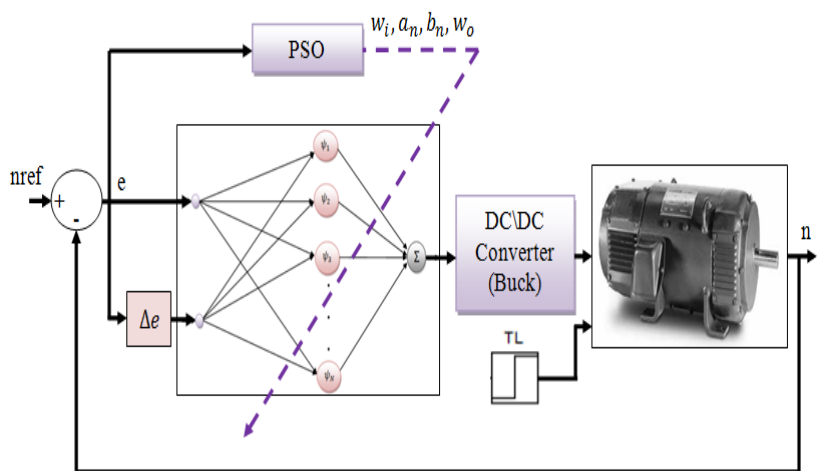

Fig 4: Block diagram of DC motor Control System

\section{SIMULATION AND RESULTS}

Let the simulation setting with simulation period $5 \mathrm{sec}$, and the following solver options: type fixed step size, solver type ode4 runge-kutta, fundamental sample time $0.01 \mathrm{sec}$. The PSO algorithm have the following values which are no of birds is 50 , Maximum iteration number is 250 , bird step is 250 , Wmax is $0.9, \mathrm{Wmin}$ is $0.25, \mathrm{c} 1$ is 2.05 and $\mathrm{c} 2$ is 2.05 . For testing the speed response of DC shunt motor, in the case of no-load and in the case of applying different torque load values;

I. When speed reference is equal to $1200 \mathrm{rpm}$, and the torque load is equal to zero (no-load), the speed response is shown in Figure (5). The starting armature current is equal to 25.7976 Amp, and the final armature current is equal to $0.2513 \mathrm{Amp}$ as shown in the Figure (6).

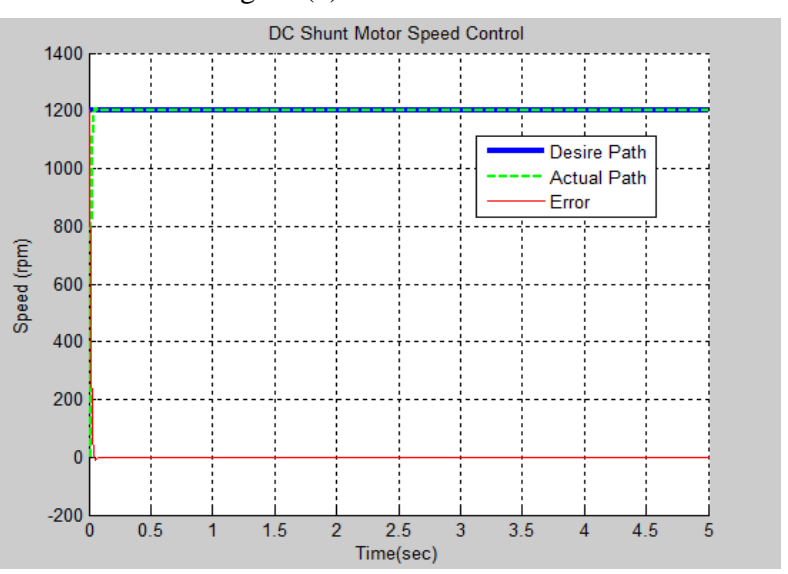

Fig 5: Speed response with no-load

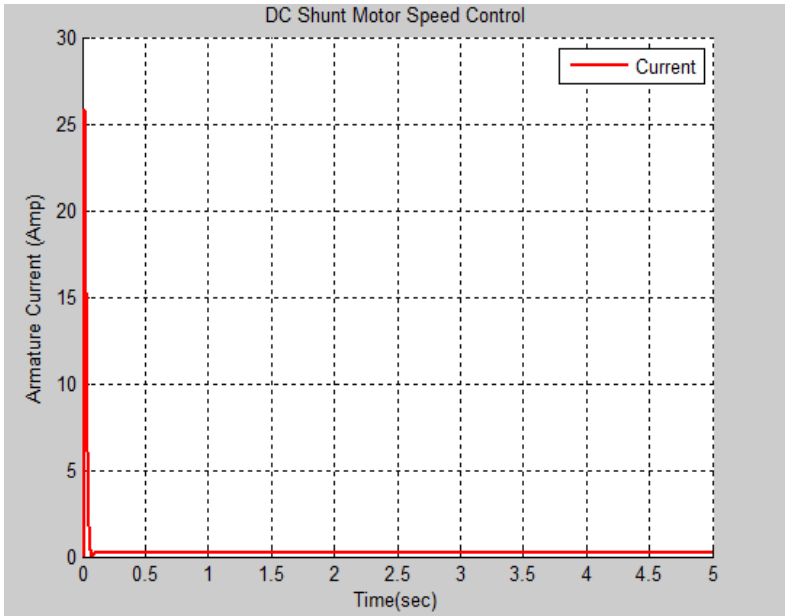

Fig 6: Armature Current with no-load

II. When speed reference is equal to $1200 \mathrm{rpm}$ and the torque load is equal to $0.1 \mathrm{~N} . \mathrm{m}$, the speed response is shown in Figure (7). The starting armature current is equal to 25.7976 Amp, and the final armature current is equal to $2.2513 \mathrm{Amp}$ as shown in the Figure (8). The torque load is applied after 0.2 sec.

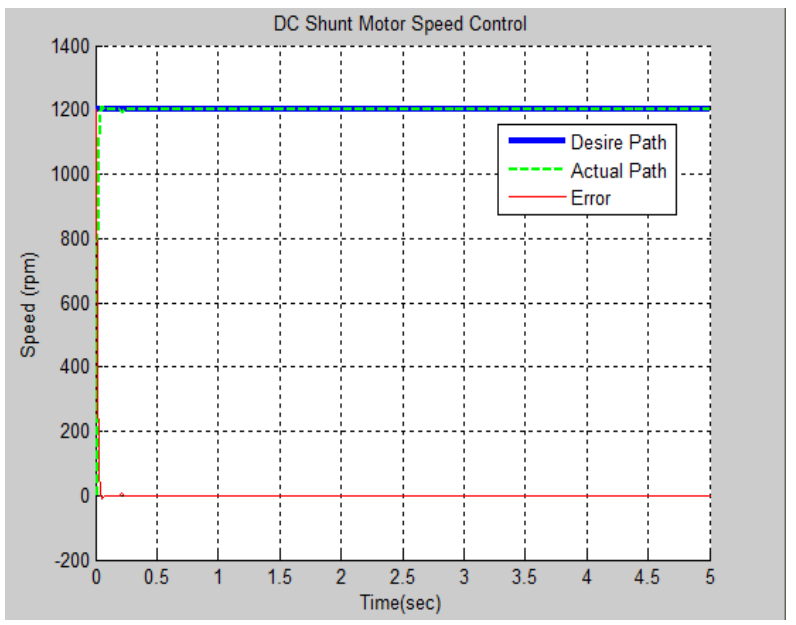

Fig 7: Speed response with 0.1 N.m torque load

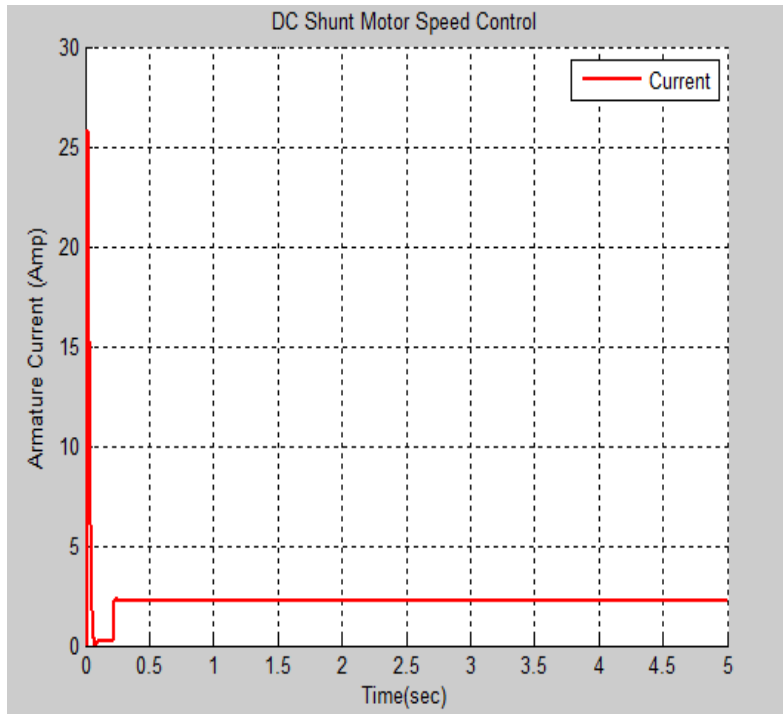

Fig 8: Armature Current with 0.1 N.m torque load 
III. When speed reference is equal to $1200 \mathrm{rpm}$, and the torque load is equal to $0.5 \mathrm{~N} . \mathrm{m}$, the speed response is shown in Figure (9). The starting armature current is equal to 25.7976 Amp, and the final armature current is equal to 10.251 Amp as shown in the Figure (10). The torque load is applied after $0.2 \mathrm{sec}$.

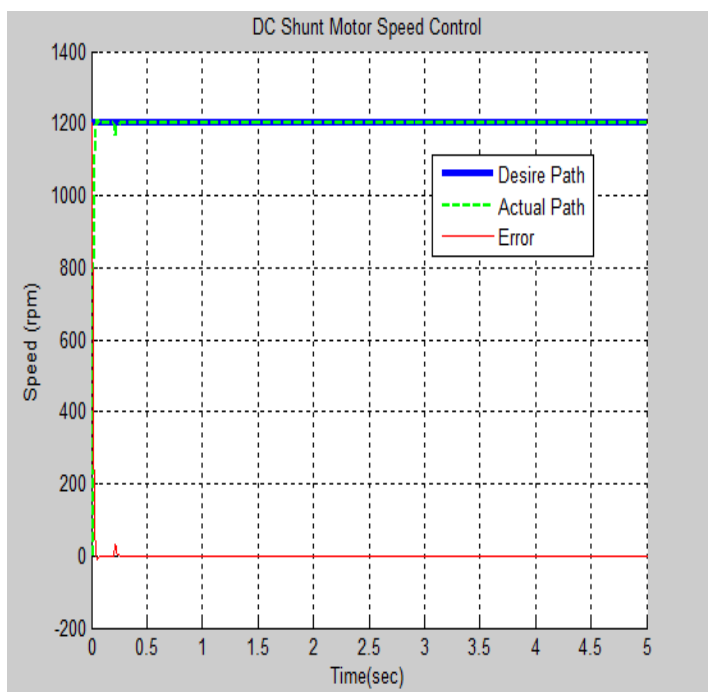

Fig 9: Speed response with 0.5 N.m torque load

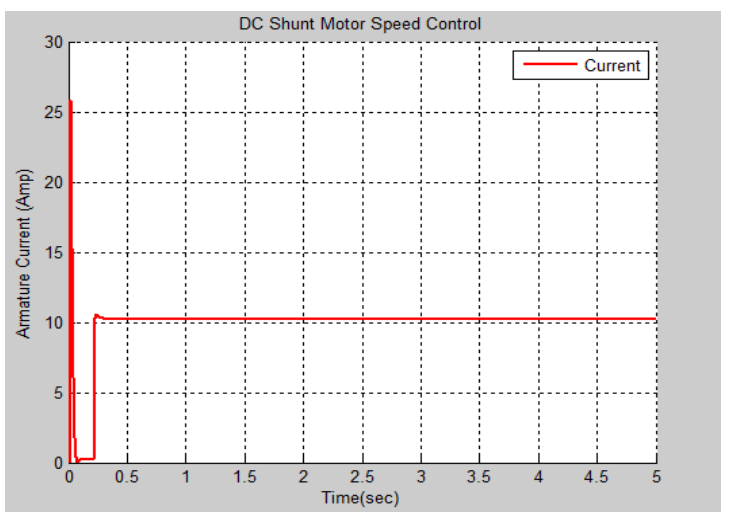

Fig 10: Armature Current with 0.5 N.m torque load

\section{CONCLUSION}

In this paper, shunt DC motor control system is implemented and tested by using matlab/simulink software package version 7.12.0 (R2011a), and the simulation results reveal that the method of using wavelet neural network as a speed controller is feasible because the wavelet neural network is succeeded to control the speed under different loads. And the deviation between the actual and desire trajectories is very small. The model shows good results under all conditions that is employed during simulation. Also, the PSO algorithm is succeeded to optimize the wavelet neural network parameters based on the mean square error values.

\section{REFERENCES}

[1] M. S. H. Lipu and T. F. Karim, "Energy Efficiency Opportunities and Savings Potential for Electric Motor and Its Impact on GHG Emissions Reduction," International Journal of Electrical and Computer Engineering (IJECE), vol. 3, no. 4, pp. 533-542, 2013.

[2] S. Shrivastava, J. Rawat and A. Agrawal, "Controlling DC Motor using Microcontroller (PIC16F72) with
PWM," International Journal of Engineering Research, vol. 1, no. 2, pp. 45-47, 2012.

[3] R. Soni, D. Singh, P. Pandey and P. Sharma, "Simulation of Optimal Speed Control for a DC Motor Using Conventional PID Controller and Fuzzy Logic Controller," International Journal of Information and Computation Technology, vol. 3, no. 3, pp. 181-188, 2013.

[4] J. S. Chauhan and S. Semwal, "Microcontroller Based Speed Control of DC Geared Motor Through RS-232 Interface With PC," International Journal of Engineering Research and Applications (IJERA), vol. 3, no. 1, pp. 778-783, 2013.

[5] H. m. Fayek and I. Elamvazuthi, "Type-2 Fuzzy Logic PI (T2FLPI) based DC Servomotor Control," Journal of Applied Sciences Research, vol. 8, no. 5, pp. 2564-2574, 2012.

[6] A. M. Adday and M. Z. .. Othman, "Combined Armature and Field Fuzzy Speed Control of a DC Motor for Efficiency Enhancement," Al-Rafidain Engineering, vol. 20, no. 6, pp. 117-129, 2012.

[7] P. K. SAHOO and N. K. BARIK, "Speed Control of Seperately Exited DC Motor Using Self Tuned Fuzzy PID Controller," National Institute of Technology, Rourkela, 2010-2011.

[8] A. FAIZY and S. KUMAR, "DC MOTOR CONTROL USING CHOPPER," Department of Electrical Engineering-National Institute of Technology , Rourkela, India .

[9] S. K. Viswanath, M. Gowtham, P. A. Kumar and K. R. Naik, "SPEED CONTROL OF A DC MOTOR USING MICROCONTROLLER 8051," ELECTRICAL AND ELECTRONICS ENGINEERING-GOKARAJU RANGARAJU INSTITUTES OF ENGINEERING AND TECHNOLOGY, HYDERABAD, 2011.

[10] H. Chen, Y. Lu and L. Tu, "Fault Identification of Gearbox Degradation with Optimized Wavelet Neural Network," Shock and Vibration, vol. 20, no. 2, pp. 247 262, 2013.

[11] Y. HUANG and S. YU, "Explosive Ordnance Disposal Robot Path Planning Based on Danger Model Immune Wavelet Neural Network," Advances in information Sciences and Service Sciences (AISS), vol. 3, no. 11.18, 2011.

[12] T. Y. Abdalla and M. I. Hamzah, "Trajectory Tracking Control for Mobile Robot using Wavelet Network," International Journal of Computer Applications, vol. 74, no. 3, pp. 32-37, 2013.

[13] Q. Bai, "Analysis of Particle Swarm Optimization Algorithm," Computer and Information Science, vol. 3, no. 1, pp. 180-184, 2010.

[14] Z. Bashir and M. EL-Hawary, "Applying Wavelets to Short-Term Load Forecasting Using PSO-Based Neural Networks," IEEE TRANSACTION ON POWER SYSTEMS, vol. 24, no. 1, pp. 20-27, 2009.

[15] J. Chao, W. Bo and H. Youmin, "Wavelet Neural Network Based on NARMA $\neg$ L2 Model for Prediction of Thermal Characteristics in a Feed System," CHINESE 
JOURNAL OF MECHANICAL ENGINEERING, vol. 23, pp. 1-10, 2010.

[16] Y. Bodyanskiy, I. Pliss and O. Vynokurova, "ADAPTIVE WAVELET-NEURO-FUZZY NETWORK IN THE FORECASTING AND EMULATION TASKS," International Journal "Information Theories \& Applications, vol. 15, pp. 47-55, 2008.

[17] B. ALLAOUA, B. GASBAOUI and B. MEBARKI, "Setting Up PID DC Motor Speed Control Alteration
Parameters Using Particle Swarm Optimization Strategy," Leonardo Electronic Journal of Practices and Technologies, no. 14, pp. 19-32, 2009.

[18] M. Tushir and S. Srivastava, "Type-2 fuzzy logic controller Implementation for tracking control of DC motor," International Journal of Computer Network and Security (IJCNS), vol. 3, no. 1, pp. 34-41. 